\title{
A FORMAÇÃO PROFISSIONAL DAS DISCIPLINAS DO EIXO FUNDAMENTAL: O EXEMPLO DO CONCEITO DE JUSTIÇA NOS LIVROS DE PROCESSO CIVIL E TEORIA DO DIREITO
}

\author{
Danilo Christiano Antunes Meira* \\ Horácio Wanderlei Rodrigues ${ }^{* *}$
}

RESUMO: A proposta do presente artigo é evidenciar um equívoco que se faz do currículo dos cursos de direito: o de que disciplinas do eixo de formação fundamental não contribuem para a formação profissional do estudante. Como argumento contrário a essa presunção, o estudo proporá uma análise comparativa. Serão comparadas diferentes exposições que o conceito operacional de justiça oferecidas por livros do eixo fundamental e por livros do eixo profissional. Embora o estudo privilegie apenas um conceito muito específico da prática jurídica, o argumento central pode ser compreendido como exemplar e estimular estudos sobre outros conceitos e perspectivas de incremento formativo.

PALAVRAS-CHAVE: Currículo; Cursos de Direito; Eixo formativo fundamental; Eixo formativo profissional; Incremento formativo.

\section{THE PROFESSIONAL FORMATION IN THE DISCIPLINES OF THE FUNDAMENTAL AXIS: THE EXAMPLE OF THE CONCEPT OF JUSTICE IN CIVIL PROCEDURE AND THEORY OF THE LAW BOOKS}

\begin{abstract}
The purpose of this article is to highlight a common misconception in the curriculum design of law courses: the presumption that the basic formative axis do not contribute to the student's professional training. As an argument against this presumption, the study will propose a comparative analysis. The different expositions that the operational concept of justice offered by books of the fundamental axis and by books of the professional axis will be compared. Although the study favors only a very specific concept of legal practice,
\end{abstract}

1 Doutorando em Direito pela UFSC. Mestre em Direito pela UFSC. Graduado em Direito pela FADISA. Pesquisador do grupo de pesquisa Fundamentos e Dimensões dos Direitos Humanos (IMED). Membro do grupo de pesquisa NECODI - Núcleo de Estudos Conhecer Direito (IMED/UFSC). Membro do grupo de pesquisa Centro de Estudos Jurídico-Econômicos e de Gestão do Desenvolvimento (UFSC). Bolsista CNPq. danchristiano@gmail.com.

2 Doutor em Direito (Filosofia do Direito e da Política) pela Universidade Federal de Santa Catarina (UFSC). Mestre em Direito (Instituições Jurídico-Políticas) pela UFSC. Realizou Estágios de Pós-Doutorado em Filosofia na Universidade do Vale do Rio dos Sinos (UNISINOS) e em Educação na Universidade Federal do Rio Grande do Sul (UFRGS). Professor Permanente do Programa de Pós-Graduação em Direito (PPG Direito) da Faculdade Meridional (IMED/RS). Professor Titular de Teoria do Processo do Departamento de Direito e Professor Permanente do Programa de Pós-Graduação Direito da UFSC, de 1991 a 2016. Coordenador do Mestrado Profissional em Direito em Direito da UFSC, de 2015 a 2016. Sócio fundador do Conselho Nacional de Pesquisa e Pós-Graduação em Direito (CONPEDI) e da Associação Brasileira de Ensino do Direito (ABEDi). Membro do Instituto Iberomericano de Derecho Procesal (IIDP). Pesquisador do Conselho Nacional de Desenvolvimento Científico e Tecnológico (CNPq) e da Fundação Meridional. Presidente da Comissão de Educação Jurídica da OAB/SC. Publicou diversos livros e uma centena de artigos em coletâneas e revistas especializadas, em especial sobre Ensino e Pesquisa em Direito, Direitos Humanos e Teoria do Processo. horaciowr@gmail.com. 
the central argument can be understood as exemplary and stimulate studies on other concepts and perspectives.

KEYWORDS: Curriculum; Law courses; Basic formative axis; Professional formative axis; Formative increase.

\section{INTRODUÇÃO}

A Resolução CNE/CES no 9/2004³ ${ }^{3}$, apoiada no Parecer CNE/CES no 55/2004 ${ }^{4}$, estabeleceu uma classificação tripartite e interligada de eixos de formação aos cursos de graduação em Direito. De acordo com o art. $5^{\circ}$ dessa resolução, os cursos devem contemplar conteúdos e atividades que atendam uma formação fundamental, uma formação profissional e uma formação prática 5 . O eixo de formação fundamental objetiva "integrar o estudante no campo, estabelecendo as relações do Direito com outras áreas do saber” e abrange, entre outros estudos, aqueles "que envolvam conteúdos essenciais sobre Antropologia, Ciência Política,

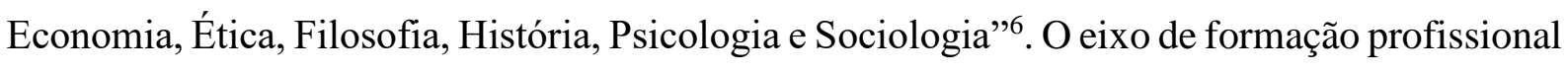
objetiva contemplar, "além do enfoque dogmático, o conhecimento e a aplicação, observadas as peculiaridades dos diversos ramos do Direito, de qualquer natureza, estudados sistematicamente e contextualizados segundo a evolução da Ciência do Direito e sua aplicação às mudanças sociais, econômicas, políticas e culturais do Brasil e suas relações internacionais" e abrange "conteúdos essenciais sobre Direito Constitucional, Direito Administrativo, Direito Tributário, Direito Penal, Direito Civil, Direito Empresarial, Direito do Trabalho, Direito Internacional e Direito Processual", além de "outros condizentes com o projeto pedagógico"7. O eixo de formação prática objetiva a "integração entre a prática e os conteúdos teóricos desenvolvidos nos demais Eixos, especialmente nas atividades relacionadas com o Estágio Curricular Supervisionado, Trabalho de Curso e Atividades Complementares" $"$.

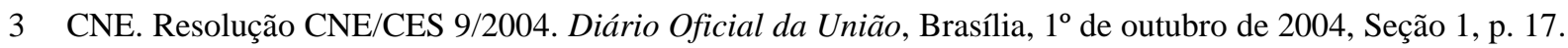
Disponível em <http://portal.mec.gov.br/cne/arquivos/pdf/rces09_04.pdf> Acessado em 13 de agosto de 2017 (embora o edital do evento tenha feito a recomendação de que as notas de referência fossem feitas no corpo do texto e não no rodapé das páginas, o presente artigo tem como peculiaridade o fato de citar livros e fontes em formato digital que demandam indicações muito precisas, como o número do capítulo, do subtópico e até do parágrafo da obra analisada. Não seria desejável omitir essas informações do leitor porque isso prejudicaria a conferência das citações. Por outro lado, inserir tais informações no corpo do texto poderia inviabilizar a sua leitura, especialmente em citações diretas extraídas de seções muito distintas. Por essas razões, consideramos necessário manter todas as indicações de referências em notas de rodapé).

4 CNE. Parecer CNE/CES 55/2004. Disponível em <http://portal.mec.gov.br/cne/arquivos/pdf/2004/ces0055_2004.pdf> Acessado em 13 de agosto de 2017.

5 Res. CNE/CES 9/2004, art. 5.

6 Res. CNE/CES 9/2004, art. 5, I.

7 Res. CNE/CES 9/2004, art. 5, II.

8 Res. CNE/CES 9/2004, art. 5º III. 
Embora os três eixos formativos tenham o mesmo caráter de obrigatoriedade, parece existir uma inclinação da maioria dos alunos, professores e coordenadores de curso no sentido de considerar os conteúdos do eixo fundamental como os menos relevantes da grade curricular. Um indicativo dessa inclinação seria a hábito de utilizar o eixo fundamental para acomodar professores menos especializados ou inaptos ${ }^{9}$. E esse hábito costuma ser justificado com duas alegações: (a) o Exame de Ordem e os outros concursos de carreiras jurídicas aferem apenas ou majoritariamente conhecimentos e habilidades adquiridos nos eixos de formação profissional e prático; e (b) os conhecimentos e habilidades proporcionados pelo eixo fundamental seriam inaplicáveis em um contexto de exercício profissional.

Sobre o ponto "a", há muito tempo já se discute a impropriedade de se pautar a graduação em Direito pela demanda de resultados em concursos ou de determinadas corporações profissionais, como a $\mathrm{OAB}^{10}$. Sobre o ponto "b", embora razoáveis, as justificativas costumam ser oferecidas de forma indireta. Às vezes simplesmente se afirma que o eixo fundamental é evidentemente relevante, que os conteúdos nele veiculados são importantes de um ponto de vista cultural. Em outras vezes, se afirma que o conteúdo do eixo fundamental proporcionaria uma formação mais crítica e mais humanista. Porém, raramente se enfrenta a tarefa de vincular diretamente o conteúdo das disciplinas e atividades do eixo fundamental aos conhecimentos e habilidades necessários para o futuro exercício profissional do graduando.

A contribuição que se pretende oferecer aqui reside justamente neste ponto: relacionar o eixo fundamental à possibilidade de incremento formativo profissional dos estudantes por uma via direta. Trata-se de verificar a assertividade de uma intuição compartilhada por muitos pesquisadores e professores, a de que obras típicas do eixo fundamental proporcionam uma compreensão mais abrangente de muitos conceitos operacionais utilizados no cotidiano profissional. Como não seria possível contemplar em poucas páginas todos os aspectos das

9 Como afirmou Rubin Assis, “a situação mais frequente nas faculdades de direito são as aulas de filosofia e de outras cadeiras do eixo fundamental serem tapeadas por qualquer bacharel sem nada melhor para fazer". SOUZA, Rubin Assis da Silveira. Técnicas pedagógicas passo-a-passo de ensino de filosofia para o jurista desocupado. Captura Críptica. Florianópolis, n.4., v.1., jan./dez. 2013. p. 9-18. Disponível em <http://capturacriptica.ccj.ufsc.br/wp-content/uploads/captura_criptica_-_v4n1_completo.pdf> Acessado em 15 de agosto de 2017.

10 Para Veronese, por exemplo, “os padrões de excelência acadêmica não podem, por óbvio, ser aferidos pela entidade que congrega a corporação dos advogados ou de qualquer outro grupo profissional jurídico. [...] Creio que o tema merece debates mais detidos, [...] ao invés de buscar debater a qualidade acadêmica dos cursos por meio do Exame de Ordem". VERONESE, Alexandre. Advogados e ensino jurídico. Jota. Disponível em <https://jota.info/colunas/judiciario-e-sociedade/judiciario-e-sociedade-advogados-e-ensinojuridico-11122015> Acessado em 13 de agosto de 2017. 
atividades e conteúdos do eixo de formação fundamental que podem impactar direta e positivamente na futura atuação profissional do graduando em Direito, optou-se por abordar apenas um ponto suficientemente exemplar: a compreensão do conceito de justiça que obras de diferentes eixos formativos proporcionam aos estudantes. Neste caso, optou-se por privilegiar essa comparação entre algumas obras clássicas de Teoria do Direito, representativas do eixo fundamental, e algumas obras de Direito Processual Civil, representativas dos eixos profissional e prático.

$\mathrm{O}$ artigo se desenvolve em quatro etapas. Na primeira etapa serão expostas as razões que justificam a adequação da abordagem e do conceito escolhidos. Na segunda etapa, de caráter descritivo, será feita uma síntese da exposição que diferentes livros de Direito Processual Civil fornecem sobre o conceito de justiça. Na terceira etapa, também descritiva, será feita uma síntese da exposição que o mesmo conceito de justiça recebe de livros de Teoria do Direito. Na quarta etapa, de caráter analítico e reflexivo, as diferentes exposições serão comparadas em termos de possibilidade formativa profissional. A conclusão, por sua vez, será reservada à síntese das considerações suscitadas nas etapas anteriores. Além de verificar a importância das atividades e conteúdos do eixo de formação fundamental à atuação prática e profissional, que é si mesmo um resultado relevante para qualquer discussão sobre os currículos e a qualidade de ensino dos cursos de Direito, espera-se que o estudo também possa servir como escopo para novas pesquisas sobre outras atividades e conteúdos que não poderiam ser abordados aqui.

\section{AS ESCOLHAS METODOLÓGICAS}

Para enfrentar o desafio de demonstrar a possibilidade de incremento formativo profissional das atividades e conteúdos do eixo fundamental, optou-se comparar como o conceito de justiça é tratado em livros desse eixo e em livros dos eixos profissional e prático. A escolha dessa estratégia, porém, precisa ser justificada.

Em primeiro lugar, essa demonstração demanda parâmetros e metodologias verificáveis e não um ensaio opinioso. A escolha por avaliar a exposição de um conceito operacional de uma perspectiva comparativa parece cumprir essa função. Desde o conceito escolhido até a própria avaliação, tudo pode ser sindicalizado por pesquisadores que eventualmente discordem dos resultados apresentados.

Sobre a relevância que um conceito operacional do âmbito jurídico tem na prática 
profissional, especialmente de conceitos que não são exclusivos das disciplinas dogmáticas, parte-se de uma premissa suficientemente segura. Nem todos os conflitos são resolvidos por uma pura operação de subsunção dos fatos juridicamente relevantes às normas jurídicas correspondentes. Existem espaços de indeterminação nos quais uma argumentação bem construída pode ser decisiva. Nesses espaços de indeterminação costumam gravitar muitos conceitos com funcionalidades específicas no âmbito jurídico. Conhecer esses conceitos significa estar em uma situação vantajosa em termos argumentativos.

A escolha do conceito de justiça justifica-se por ser um dos mais recorrentes em teses e argumentações jurídicas. Uma simples consulta ao serviço de pesquisa de jurisprudência do STF, por exemplo, indica que ele já foi utilizado em nada menos que 52.181 acórdãos e 152.137 decisões monocráticas daquele tribunal ${ }^{11}$. Em muitas dessas decisões, obviamente, o termo é empregado apenas como sinônimo do conjunto de órgãos que formam o poder judiciário ou uma das jurisdições encarregadas de administrá-lo, como nas expressões justiça do trabalho ou morosidade da justiça. Nesses casos, até interlocutores que não têm familiaridade com o vocabulário jurídico partilham razoavelmente a mesma compreensão do que se quer dizer por justiça. Mas há também acórdãos e decisões monocráticas nos quais se fala em justiça para significar uma maneira justa de decidir um conflito. Às vezes nem é preciso procurar pelo termo para se perceber manifestações de ministros, juízes, procuradores, advogados, partes e demais atores de um processo judicial que são típicas de quem reivindica a materialização da justiça como sinônimo do que é justo. Aqui, porém, os interlocutores costumam discordar sobre aquilo que se entende por justiça e, não raro, essa discordância torna-se um obstáculo mais significativo que o próprio problema jurídico subjacente. E esses obstáculos não são óbvios para alunos de graduação. De certo modo, a compreensão dos problemas que envolvem a utilização do termo justiça especificamente como sinônimo do que é justo é requisito para os raciocínios mais básicos da prática jurídica.

Optou-se por verificar como o conceito de justiça é tratado nos livros de Direito Processual Civil, e não em livros de outros ramos, por uma série de fatores. O mais relevante é que são livros dos eixos profissional e prático por excelência. São eles que os professores utilizam nas aulas que preparam o estudante para atuar profissionalmente no maior campo do Direito e que funciona, ao mesmo tempo, como fonte subsidiária para os demais. São livros atualizados e colocados em evidência pela ocasião da promulgação do novo código, o que gera

11 STF. Pesquisa de Jurisprudência. $\quad$ Disponível em <http://www.stf.jus.br/portal/jurisprudencia/pesquisarJurisprudencia.asp> Acessado em 13 de agosto de 2017. 
presunção de atualidade. Além disso, os seus capítulos introdutórios costumam ser concebidos como uma oportunidade de familiarizar o estudante a elementos e conceitos cuja compreensão, como a do próprio conceito de justiça, é requisito para a assimilação de conteúdos mais avançados. Essa razão justifica a opção desse estudo em privilegiar a exposição do conceito de justiça apenas nos primeiros volumes das séries ou volumes únicos. Por fim, e não menos importante, a escolha de apenas um ramo e não de vários ramos do Direito se dá pela impossibilidade de avaliar com atenção todas as ocorrências das palavras "justiça" e "justo" em todos os livros de todas as áreas. Uma avaliação de poucos exemplares de cada uma das disciplinas dos eixos profissional e prático também se mostraria problemática porque, demasiadamente aleatória, ela não sustentaria nenhum resultado com segurança.

Parece adequado, portanto, verificar como os livros desses diferentes eixos abordam um conceito operacional muito empregado na prática jurídica como estratégia de aferição dos seus respectivos potenciais formativos. Caso se confirme a hipótese de que eles apresentam o conceito de forma distinta, torna-se viável uma comparação que permita avaliá-los qualitativamente em termos de possibilidade de incremento formativo profissional.

\section{O CONCEITO DE JUSTIÇA NOS LIVROS DE DIREITO PROCESSUAL CIVIL}

A localização das exposições sobre o conceito de justiça nos livros de Direito Processual Civil foi efetuada pela busca dos termos "justiça" e "justo". Como observado no tópico anterior, privilegiou-se aqui apenas os primeiros volumes das séries ou volumes únicos. Os livros utilizados foram Manual de Direito Processual Civil, de Cássio Scarpinella Bueno ${ }^{12}$; O Novo Processo Civil Brasileiro, de Alexandre Freitas Câmara ${ }^{13}$; Curso de Direito Processual Civil, Vol. I, de Humberto Theodoro Jr. ${ }^{14}$; Novo curso de processo civil, Vol. I, de Luiz Guilherme Marinoni, Sérgio Cruz Arenhart e Daniel Mitidiero ${ }^{15}$; Curso de Direito Processual Civil, Vol. I, de Fredie Didier Jr. ${ }^{16}$; Curso Didático de Direito Processual Civil, de Elpídio

12 BUENO, Cassio Scarpinella. Manual de direito processual civil: inteiramente estruturado à luz do novo CPC - Lei n. 13.105, de 16-3-2015. São Paulo: Saraiva, 2015.

13 CÂMARA, Alexandre Freitas. O novo processo civil brasileiro. 3. ed. São Paulo: Atlas, 2017.

14 THEODORO JÚNIOR, Humberto. Curso de Direito Processual Civil: Teoria geral do direito processual civil, processo de conhecimento e procedimento comum - vol. I. 56. ed. rev., atual. e ampl. Rio de Janeiro: Forense, 2015.

15 MARINONI, Luiz Guilherme; ARENHART, Sérgio Cruz; MITIDIERO, Daniel. Novo curso de processo civil: teoria do processo civil. Vol. 1. 3. ed. rev., atual. e ampli. São Paulo: Editora Revista dos Tribunais, 2017.

16 DIDIER JÚNIOR, Fredie. Curso de Direito Processual Civil: introdução ao direito processual civil, parte geral e processo de conhecimento. Vol. 1. 17. ed. Salvador: Editora Jus Podivm, 2015. 
Donizetti $^{17}$; Curso de Direito Processual Civil, de Mizael Montenegro Filho ${ }^{18}$; e Manual de Direito Processual Civil, de Daniel Amorim Assumpção Neves ${ }^{19}$.

Nos livros Manual de Direito Processual Civil, Cássio Scarpinella Bueno, e O Novo Processo Civil Brasileiro, Alexandre Freitas Câmara, não há ocorrências das palavras "justiça" e "justo" empregadas em sentido relevante para a compreensão do conceito de justiça como sinônimo do que é justo.

No livro Curso de Direito Processual Civil, Vol. I, de Humberto Theodoro Júnior, há ocorrências relevantes das palavras "justiça" e "justo" especialmente no tópico 32, quando se fala sobre processo justo. O autor afirma que o adjetivo justo atribui ao processo uma "significativa carga ética, tanto na regulação procedimental como na formulação substancial dos provimentos decisórios" ${ }^{20}$, mas sem implicar uma submissão do Direito ao campo da Moral, dado que ambos possuem campos distintos de incidência. A questão que se coloca, portanto, é a de saber o que é essa carga ética significa para o autor. Em primeiro lugar, ele concebe o campo moral, no qual se encontra o conceito de justiça, como subjetivo ${ }^{21}$, mas desenvolve e defende uma concepção muito particular como a maneira correta de compreender o termo no contexto processual. É uma concepção de justiça como sinônimo de equidade: o adjetivo justo implica um processo que não seja paternalista ou assistencial, que respeite os princípios constitucionais da legalidade, da liberdade e da igualdade, que privilegie a efetividade da prestação jurisdicional ${ }^{22}$. Por fim, é importante notar que o autor compreende que a moral "se

17 DONIZETTI, Elpídio. Curso didático de direito processual civil. 19. ed. revisada e completamente reformulada conforme o Novo CPC - Lei 13.105, de 16 de março de 2015 e atualizada de acordo com a Lei 13.256, de 04 de fevereiro de 2016. São Paulo: Atlas, 2016.

18 MONTENEGRO FILHO, Mizael. Curso de Direito Processual Civil. 12. ed. ref. e atual. São Paulo: Atlas, 2016.

19 NEVES, Daniel Amorim Assumpção. Manual de direito processual civil. 8. ed. Salvador: Editora Jus Podivm, 2016.

20 THEODORO JÚNIOR, 2015, tópico 32, §1 (como a numeração de página de livros digitais varia conforme de dispositivo a dispositivo, optou-se por utilizar indicadores alternativos mais adequados para a localização da citação).

21 Para o autor, "justo e injusto medem-se, no processo, pelos padrões objetivos próprios do direito, e não pela ótica subjetiva e intimista da moral, mesmo porque não é possível na ordem prática quantificar e delimitar, com precisão, os valores e preceitos puramente éticos, em todo seu alcance in concreto" (THEODORO JÚNIOR, 2015, tópico 32, §5º.

22 Os argumentos que permitiram essa síntese podem ser lidos nessas transcrições: "não se admite que o provimento judicial se torne fonte primária de uma justiça paternalista e assistencial, alheia ou contrária aos preceitos editados pelo legislador. [...] É pela equidade que o valor moral penetra na aplicação judicial do direito. [...] É, pois, pela prevalência dos princípios constitucionais de liberdade e igualdade, sobretudo, que se realiza a equidade e se repele a iniquidade na composição dos conflitos jurídicos. [...] o processo justo, em que se transformou o antigo devido processo legal, é o meio concreto de praticar o processo judicial delineado pela Constituição para assegurar o pleno acesso à Justiça e a realização das garantias fundamentais traduzidas nos princípios da legalidade, liberdade e igualdade. [...] o processo, para ser justo, nos moldes constitucionais do Estado Democrático de Direito, terá de consagrar, no plano procedimental: a) o direito de acesso à Justiça; b) o direito de defesa; c) o contraditório e a paridade de armas (processuais) entre as partes; d) a independência 
volta acima de tudo para o aperfeiçoamento íntimo da pessoa e se sujeita a sanções também íntimas e pessoais".

No livro Novo Curso de Processo Civil, de Marinoni, Arenhart e Mitidiero, uma das principais ocorrências relevantes é aquela na qual se afirma que a justiça não é mais critério de validade da norma jurídica ${ }^{23}$. Ao falar sobre o potencial de equivocidade dos textos das normas, os autores também observam que a justiça tem um caráter relativo: a compreensão do que é justo é tão variada como os diferentes interesses e concepções dos intérpretes ${ }^{24}$. Ao justificar o controle de constitucionalidade das leis, os autores argumentam que os princípios de justiça positivados na Constituição devem funcionar como critérios de controle substancial ${ }^{25}$. Também argumentam que a atual relevância dos princípios de justiça (enquanto normas constitucionais e não valores abstratos) no controle de constitucionalidade atribui uma tarefa diferente à doutrina: ela deve corrigir e adequar a lei aos princípios de justiça, e não apenas descrevê-la ${ }^{26}$.

e a imparcialidade do juiz; e) a obrigatoriedade da motivação dos provimentos judiciais decisórios; f) a garantia de uma duração razoável, que proporcione uma tempestiva tutela jurisdicional. [...] No plano substancial, o processo justo deverá proporcionar a efetividade da tutela àquele a quem corresponda a situação jurídica amparada pelo direito, aplicado à base de critérios valorizados pela equidade concebida, sobretudo, à luz das garantias e dos princípios constitucionais. [...] O processo justo, na concepção constitucional, não é o programado para ir além do direito positivado na ordem jurídica: é apenas aquele que se propõe a outorgar aos litigantes a plena tutela jurisdicional, segundo os princípios fundamentais da ordem constitucional (liberdade, igualdade e legalidade). [...] Proporcionar justiça, em juízo, consiste, nada mais, nada menos, que (i) distribuir igualmente 'as limitações da liberdade', para que todos tenham protegida a própria liberdade; e (ii) fazer que, sem privilégios e discriminações, seja dispensado tratamento igual a todos perante a lei” (THEODORO JÚNIOR, 2015, tópico 32, do $§ 5^{\circ}$ ao $\left.§ 10\right)$.

23 "O princípio da legalidade, assim, acabou por constituir um critério de identificação do direito: o direito estaria apenas na norma jurídica, cuja validade não dependeria de sua correspondência com a justiça, mas somente de ter sido produzida por uma autoridade dotada de competência normativa. [...] nessa dimensão a juridicidade da norma está desligada de sua justiça intrínseca, importando somente se foi editada por uma autoridade competente e segundo um procedimento regular" (MARINONI; ARENHART; MITIDIERO, 2017, capítulo 1 , subtítulo $\left.1.1, \S 5^{\circ}\right)$.

24 “a equivocidade não é propriamente um defeito objetivo do texto, mas uma decorrência de diferentes interesses e concepções a respeito da justiça dos intérpretes e da multiplicidade de concepções dogmáticas e métodos interpretativos por eles utilizados que interferem na atividade de individualização, valoração e escolha de significados. A interpretação varia de acordo com a posição assumida pelo intérprete na sociedade ou diante de determinado conflito (diferentes interesses), com as suas inclinações ético -políticas (concepções de justiça), com os conceitos jurídicos de que se vale (concepções dogmáticas) e com os argumentos interpretativos eleitos (métodos interpretativos)" (MARINONI; ARENHART; MITIDIERO, 2017, capítulo 2, subtítulo 2.5, $\$ 5^{\circ}$ ).

25 "jamais se poderia concluir que o texto da lei é perfeito, e assim deve ser simplesmente proclamado pelo juiz, apenas por ser o resultado de um procedimento legislativo regular. De modo que se tornou necessário resgatar a substância da lei e, mais do que isso, encontrar os instrumentos capazes de permitir a sua limitação e conformação aos princípios de justiça. Tal substância e esses princípios tinham que ser colocados em uma posição superior e, assim, foram infiltrados nas Constituições. [...] não há mais qualquer legitimidade na velha ideia de jurisdição voltada à atuação da lei; não é possível esquecer que o Judiciário deve compreendê -la e interpretá-- la a partir dos princípios constitucionais de justiça e dos direitos fundamentais" (MARINONI; ARENHART; MITIDIERO, 2017, capítulo 3, subtítulo 3.2, do $\S 4^{\circ}$ ao $\S 6^{\circ}$ ).

26 "Se a lei passa a se subordinar aos princípios constitucionais de justiça e aos direitos fundamentais, a tarefa da doutrina deixa de ser a de simplesmente descrever a lei. Cabe agora ao jurista, seja qual for a área da sua especialidade, em primeiro lugar compreender a lei à luz da Constituição, em especial dos princípios 
Além disso, os autores fazem uma relação entre os princípios materiais de justiça da constituição, o direito natural e o positivismo: "a relação que o intérprete faz, através da sua argumentação, entre a lei e o direito natural, pode ser comparada com a que se estabelece entre a lei e os princípios", mas dado que a "Constituição é uma criação política, é evidente que os direitos se fundam em algo que foi elaborado pela vontade humana e não na natureza das coisas". Por fim, cumpre observar que o conceito de justiça é muitas vezes utilizado sem um sentido preciso, como se fosse autoevidente ${ }^{27}$.

No livro Curso de Direito Processual Civil, Vol. 1, de Fredie Didier Jr., embora exista uma atenção especial em tratar dos direitos fundamentais e princípios constitucionais, a única ocorrência relevante da palavra justiça se dá quando o autor afirma que "as cláusulas gerais [processuais] servem para a realização da justiça do caso concreto; revelam-se, em feliz metáfora doutrinária, como 'pontos de erupção da equidade""28.

No livro de Elpídio Donizetti, Curso Didático de Direito Processual Civil, o conceito de justiça é utilizado em uma primeira ocorrência relevante como um juízo de valor variável, mas aparentemente passível de ser determinável objetivamente em um caso concreto através da interpretação conforme a constituição ${ }^{29}$. Outras ocorrências relevantes são vistas quando o autor relaciona o caráter de processo justo à efetividade, celeridade e adequação da tutela ${ }^{30}$ e quando ele assume que o critério de justiça deve ser utilizado como forma de controle do conteúdo das decisões judiciais ${ }^{31}$.

No livro Curso de Direito Processual Civil, de Mizael Montenegro Filho, o conceito

constitucionais e dos direitos fundamentais" (MARINONI; ARENHART; MITIDIERO, 2017, capítulo 3, subtítulo $3.3, \S 1^{\circ}$ ).

27 “a percepção da insuficiência da técnica representativa para a realização da justiça social fez com que se passasse a falar em democratizar a democracia através da participação, mediante a otimização da participação direta dos cidadãos no poder. [...] Se as situações de direito material são várias, deve-se procurar a justiça do caso concreto, o que repele as teses de que a lei poderia controlar o poder do juiz em toda e qualquer hipótese" (MARINONI; ARENHART; MITIDIERO, 2017, capítulo 2, subtítulo 2.4, §3º , e capítulo 2, subtópico 2.5, $\S 12)$.

28 DIDIER, Fredie. 2015, p. 52.

29 Nas palavras do autor, deve o magistrado "cotejar o texto da lei com a Constituição, valendo-se dos recursos de hermenêutica constitucional para extrair da legislação aplicável ao caso concreto o conceito de justiça mais adequado à tutela dos interesses postos em juízo" (DONIZETTI, 2016, capítulo 2, subtópico 2.2.5, $\S 3^{\circ}$ ).

30 “'O 'modelo constitucional do processo' nada mais é, portanto, do que o resultado da interpretação das leis processuais a partir da necessidade de que o direito fundamental a um processo justo (tutela jurisdicional efetiva, célere e adequada) seja respeitado, consoante os princípios e garantias constitucionais processuais" (DONIZETTI, 2016, capítulo 1, subtópico 1.2, §5%).

31 "O devido processo legal substancial constituiu verdadeira forma de se controlar o conteúdo das decisões judiciais (o justo no caso concreto) e das leis. Não basta, por exemplo, que a sentença seja formalmente regular, mas injusta, incorreta. Da mesma forma, violará a garantia ao devido processo legal substancial a lei formalmente válida, mas que suprima o direito fundamental ao contraditório" (DONIZETTI, 2016, capítulo 3, subtópico $3.1, \S 9^{\circ}$ ). 
de justiça pode ser compreendido de várias formas distintas em uma mesma passagem. $\mathrm{Na}$ primeira ocorrência, a justiça é vista principalmente como sinônimo de aplicação do direito, mas também há espaço para interpretá-la como sinônimo de assistência aos mais necessitados ${ }^{32}$. Em outra ocorrência, o autor parece pressupor que o conceito de justiça tenha um conteúdo específico, cuja compreensão poderia ser assimilada durante a formação do profissional ${ }^{33}$.

Por fim, para Daniel Amorim Assumpção Neves, em seu livro Manual de Direito Processual Civil, o conceito de justiça do mundo atual parece ser algo cujo conteúdo é incompatível com o princípio da legalidade. Seria compatível, porém, com a criação da norma jurídica para o caso concreto por um método que considerasse os direitos fundamentais e os princípios constitucionais de justiça ${ }^{34}$. Falando do princípio do devido processo legal, o autor também parece conceber o ideal de justo e os valores essenciais à sociedade como elementos cognoscíveis pelo juiz na decisão de um caso concreto ${ }^{35}$.

\section{O CONCEITO DE JUSTIÇA NOS LIVROS DE TEORIA DO DIREITO}

A localização das exposições sobre o conceito de justiça nos livros de Teoria do Direito também foi efetuada pela busca dos termos "justiça" e "justo". Os livros utilizados foram O Problema da Justiça, de Hans Kelsen ${ }^{36}$; Ética e Direito, de Chaïm Perelmann ${ }^{37}$; e Direito e Justiça, de Alf Ross ${ }^{38}$.

Para Hans Kelsen, a justiça é uma "qualidade ou atributo que pode ser afirmado de

32 “o processo civil não pode mais ser visto como o fim, mas como o meio para o alcance daquele, que é o de distribuir Justiça, conferindo o direito ao seu titular, denominado jurisdicionado, que nada mais é do que a pessoa (física ou jurídica) que muitas vezes depende do processo para a sua própria sobrevivência, no caso das pessoas naturais, ou para a manutenção da sua existência, no das jurídicas" (MONTENEGRO FILHO, 2016, Introdução, $\left.\S 3^{\circ}\right)$.

33 " [...] e estudo do processo, sem essa compreensão, importa na perda de tempo e na formação de profissionais dissociados do sentimento de Justiça, reclamado pela importância dos direitos em litígio" (MONTENEGRO FILHO, 2016, Introdução, $\$ 4^{\circ}$ ).

34 "Contemporaneamente, notou-se que tais formas de enxergar a jurisdição estavam fundadas em um positivismo acrítico e no princípio da supremacia da lei, o que não mais atendia as exigências de justiça do mundo atual. Dessa forma, autorizada doutrina passa a afirmar que a jurisdição deveria se ocupar da criação no caso concreto da norma jurídica, resultado da aplicação da norma legal à luz dos direitos fundamentais e dos princípios constitucionais de justiça” (NEVES, 2016, capítulo 1, subtópico 1.1, $4^{\circ}$ ).

35 "Tratando-se de um princípio-base, com conceito indeterminado, bastaria ao legislador constituinte, no tocante aos princípios processuais, se limitar a prever o devido processo legal, que na prática os valores essenciais à sociedade e ao ideal do justo dariam elementos suficientes para o juiz no caso concreto perceber outros princípios derivados do devido processo legal” (NEVES, 2016, capítulo 3, subtópico 3.4.1, $3^{\circ}$ ).

36 KELSEN, Hans. O problema da justiça. Trad. João Baptista Machado. $3^{\text {a }}$ ed. São Paulo: Martins Fontes. 1998.

37 PERELMANN, Chaïm. Ética e Direito. Trad. Maria Ermantina Galvão G. Pereira. São Paulo: Martins Fontes, 1996.

38 ROSS, Alf. Direito e Justiça. Trad. Edson Bini. Rev. Alysson Leandro Mascaro. Bauru: EDIPRO, 2000. 
diferentes objetos"39. Elementos metafísico, inexistentes "no tempo e no espaço", não podem ser considerados justos ou injustos porque "o que é avaliado, o que pode ser valioso ou desvalioso, ter um valor positivo ou negativo é a realidade" 40 . Além disso, normas de justiça seriam apenas as normas morais de caráter social, isto é, só se poderia compreender como valioso ou justo "a conduta de indivíduos em face de outros indivíduos" 41 . O suicídio, por exemplo, poderia ser considerado moral ou imoral, mas não justo ou injusto ${ }^{42}$. Uma consequência dessa centralidade da conduta humana seria a impossibilidade de se avaliar imediatamente e validar as normas jurídicas pelo caráter de justiça das mesmas ${ }^{43}$. Por outro lado, e desde que se considere que a norma jurídica pressupõe uma conduta humana que a põe no mundo do ser, o conceito de justiça permitiria avaliar, mediatamente, instituições e circunstâncias criadas por normas em relação aos indivíduos, tal como se passa no senso comum. Em qualquer caso, a validade da norma continuaria independente dessa avaliação de justiça. Essa distinção de uso imediato e mediato do atributo justiça também cria um atalho à percepção da responsabilidade pressuposta nas avaliações de justiça: sendo a justiça a qualidade de uma conduta que consiste no tratamento dado a outros homens, haverá um responsável pela justiça ou injustiça ${ }^{44}$. Outra observação importante sobre a compreensão do conceito de justiça é feita por Kelsen em termos de distinção entre normas de justiça de tipo metafísico e normas de justiça de tipo racional. As primeiras, normas de justiça do tipo metafísico, "caracterizam-se pelo fato de se apresentarem, pela sua própria natureza, como procedentes de uma instância transcendente, existente para além de todo o conhecimento humano experimental (baseado na experiência), pelo que pressupõem essencialmente a crença na existência de uma tal instância transcendente". São metafísicas também "por seu conteúdo, na medida em que não podem ser compreendidas pela razão humana. O homem deve acreditar na justiça que elas constituem - tal como acredita na existência da instância de que elas procedem-, mas não pode compreender racionalmente essa justiça". Nesses termos, o ideal da justiça metafísica "é, como a instância da qual ele provém, absoluto: de conformidade com o seu próprio sentido imanente, exclui a possibilidade de qualquer outro ideal de justiça" ${ }^{45}$. Normas de justiça de tipo racional, por outro

39 KELSEN, 1988, p. 3.

40 KELSEN, 1998, p. 4-5.

41 KELSEN, 1998, p. 4.

42 KELSEN, 1998, p. 4.

43 “a justiça e a injustiça, que são afirmadas como qualidades de uma norma jurídica positiva cuja validade é independente desta sua justiça ou injustiça, não são - ou não são imediatamente, pelo menos - qualidades desta norma, mas qualidades do ato pelo qual ela é posta, do ato de que ela é o sentido" (KELSEN, 1998, p. 9).

44 KELSEN, 1998, p. 4.

45 KELSEN, 1998, p. 16-17. 
lado, são aquelas “caracterizadas pelo fato de não pressuporem como essencial nenhuma crença na existência de uma instância transcendente, pelo fato de poderem ser pensadas como estatuídas por atos humanos postos no mundo da experiência e poderem ser entendidas pela razão humana, isto é, ser concebidas racionalmente" 46 . Isso não significa, porém, que as normas de justiça sejam encontradas na razão humana, como um valor de justiça absoluto à espera de ser descoberto por algum método. Como observa Kelsen, quando uma norma de justiça "prescreve um determinado tratamento dos homens" e se apresenta "com a pretensão de ser a única válida", isto é, "quando exclui a possibilidade de qualquer outra norma que prescreva um diferente tratamento dos homens" $"$, ela constitui um valor absoluto e "uma tal norma de justiça, constitutiva de um valor absoluto, apenas pode - como já se acentuou - provir de uma autoridade transcendente" 48 . Isso significa afirmar a possibilidade de uma pluralidade de princípios de justiça. Como ele observa, se "partirmos de um ponto de vista racional-científico, não-metafísico, e reconhecermos que há muitos ideais de justiça diferentes uns dos outros e contraditórios entre si, nenhum dos quais exclui a possibilidade de um outro, então apenas nos será lícito conferir uma validade relativa aos valores de justiça constituídos através destes ideais" $"$.

Assim como Hans Kelsen, Chaïm Perelmann também considerava o conceito de justiça como um juízo moral de valor subjetivo. E também considerava equivocada qualquer tentativa de estabelecer um sentido ou um valor que fosse o único ou o melhor para o conceito de justiça. Ele expõe esses pontos em uma análise dos princípios orientadores de diversas concepções de justiça, mostrando como são problemáticas e inconciliáveis ${ }^{50}$. O primeiro princípio verificado é o princípio a cada qual a mesma coisa, que teria o problema de desconsiderar circunstâncias particulares cuja inobservância em casos concretos configuraria uma situação injusta; o segundo princípio é o a cada qual segundo os seus méritos, cujo problema se dá na indefinição do critério de mérito; o terceiro é o a cada qual segundo as suas obras, que teria o problema de não avaliar a intenção ou o sacrifício envolvido na ação; o quarto é o a cada qual segundo suas necessidades, que aproxima a avaliação da justiça das circunstâncias contingenciais do indivíduo, como sua idade, saúde, encargos familiares, etc., e seu problema estaria na não consideração dos méritos; o quinto princípio é o a cada qual

46 KELSEN, 1998, p. 17.

47 KELSEN, 1998, p. 17.

48 KELSEN, 1998, p. 68.

49 KELSEN, 1998, p. 17-18.

50 PERELMANN, 1996, p. 9-13. 
segundo sua posição, fórmula aristocrática da justiça habitualmente sustentada pela força, o que, por si, já poderia configurar uma situação de injustiça; e o sexto princípio é o a cada qual segundo o que a lei lhe atribui, paráfrase do princípio romano cuique suum, cujo problema se dá na medida em que qualquer atribuição legal será considerada justa. Como ele sintetiza, diversos indivíduos em disputa poderiam reivindicar a justiça de sua pretensão apoiando-se em quaisquer princípios de justiça e que “pode não haver nenhuma má-fé nessas afirmações contraditórias [acerca de qual pretensão é justa]. Cada um dos antagonistas pode estar sendo sincero e acreditar que sua causa é a única justa. E ninguém se engana, pois cada qual fala de uma justiça diferente" 51 . Por outro lado, ele considera que o valor de justiça não pode ser algo totalmente arbitrário. Ao justificar a sua preocupação de indefinição do conceito de justiça, o autor reconhece a força social que está implícita no seu uso. Para ele, não seria "indiferente que se defina a justiça, o bem, a virtude, a realidade, deste ou daquele modo, pois com isso se determina o sentido conferido a valores reconhecidos, aceitos, a instrumentos muito úteis na ação, que constituem verdadeiras forças sociais" ${ }^{52}$. Além dessas considerações, Perelmann apresentou razões para se abandonar o apego por um ideal arbitrário de justiça em favor de juízos casuísticos de justiça ${ }^{53}$.

O dinamarquês Alf Ross foi outro teórico do Direito que se ocupou dos problemas de justiça, especialmente pelo interesse no esclarecimento das confusões que se encontram ligadas ao próprio conceito. Como ele observou, “a idéia de justiça parece ser uma idéia clara e simples dotada de uma poderosa força motivadora. Em todas as partes parece haver uma compreensão instintiva das exigências de justiça”. Por outro lado, complementa Ross, "o próprio fato dessa aplicabilidade quase onipresente do princípio de justiça, desperta a suspeita de que algo 'não anda bem' com uma idéia que pode ser invocada em apoio de qualquer causa" ${ }^{44}$. Para ele, "invocar a justiça é como dar uma pancada numa mesa: uma expressão emocional que faz da própria exigência um postulado absoluto", um modo inadequado "de obter entendimento mútuo" porque impossibilita "uma discussão racional" "55. O conceito de justiça, por um lado, "incita à

51 PERELMANN, 1996, p. 8.

52 PERELMANN, 1996, p. 5.

53 “um sistema normativo, seja ele qual for, contém sempre um elemento arbitrário, o valor afirmado por seus princípios fundamentais que, eles, não são justificados. Esta última arbitrariedade, é logicamente impossível evitá-la. [...] Essa imperfeição de todo sistema de justiça, a parte inevitável de arbitrariedade que contém, deve sempre estar presente na mente de quem quiser aplicar suas mais extremas consequências. É somente em nome de uma justiça perfeita que seria moral afirmar pereat mundus, fiat justitia. Mas todo sistema normativo imperfeito, para ser moralmente irrepreensível, deveria aquecer-se no contacto de valores mais imediatos e mais espontâneos" (PERELMANN, 1996, p. 67).

54 ROSS, 2000 , p. 314.

55 ROSS, 2000, p. 320. 
crença de que a exigência de alguém não é meramente a expressão de um certo interesse em conflito com interesses opostos, mas, sim, que possui uma validade superior, de caráter absoluto; e, por outro lado, exclui todo argumento e discussão racionais que visem a um acordo" 56 . Como Kelsen, Ross argumenta que as palavras justo e injusto perdem ainda mais significado descritivo quando utilizadas para caracterizar uma regra geral ou um ordenamento. A afirmação de que o sistema tributário é injusto, por exemplo, "não indica nenhuma qualidade discernível nas regras; não apresenta nenhuma razão para sua atitude. Simplesmente se limita a manifestar uma expressão emocional. Tal pessoa diz: 'Sou contra essa regra porque é injusta'. O que deveria dizer é: 'Esta regra é injusta porque sou contra ela" ${ }^{\circ 57}$. Na verdade, complementa Ross, "a idéia formal de igualdade ou justiça como estrela polar para a orientação político-social carece de todo significado", dado que seria "possível advogar a favor de qualquer postulado material em nome da justiça. [Todavia, seria] demasiado esperar que isto mude no futuro", pois é "muito fácil crer nas ilusões que excitam as emoções pelo estímulo das glândulas suprarrenais" ${ }^{\text {58 }}$.

\section{CONCLUSÃO}

Mesmo sem comparar o mérito de cada uma das exposições que os livros de Direito Processual Civil e Teoria do Direito oferecem sobre o conceito de justiça, parece evidente a existência de diferentes potenciais formativos. Os livros de Direito Processual Civil, representantes dos eixos formativos profissional e prático, não problematizam o conceito de justiça com a mesma abrangência e profundidade dos livros de Teoria do Direito, representantes do eixo de formação fundamental. Nas poucas vezes em que os primeiros propuseram uma exposição do conceito de justiça, a maior parte era limitada ao âmbito de especialização da respectiva disciplina dogmática. E ainda que seja razoável aceitar essa abordagem limitada ao contexto da disciplina dogmática, muitas exposições poderiam ser consideradas equivocadas pela perspectiva dos autores de Teoria do Direito. Isto é, a assimilação das exposições oferecidas pelos livros da Teoria do Direito, caso corretas, permitiriam não apenas uma compreensão mais abrangente do próprio conceito de justiça, mas também permitiria perceber os equívocos de alguns autores do Direito Processual Civil.

Nesses termos, caso se considere que o conceito de justiça é um conceito operacional

56 ROSS, 2000, p. 320.

57 ROSS, 2000, p. 320.

58 ROSS, 2000, p. 320. 
relevante e que o caráter de abrangência da compreensão que se faz dele se traduz em capacidade de formular argumentos e teses na prática jurídica, ao menos nesse ponto é possível concluir que os livros de Teoria do Direito, obras do eixo formativo fundamental, têm um potencial formativo profissional próprio. Embora os limites impostos ao presente estudo não permitam generalizações, parece claro que o resultado apresentado enfraquece a presunção de que as atividades e conteúdos do eixo fundamental não têm relevância de uma perspectiva formativa profissional e prática. O que foi feito aqui com o conceito de justiça pode ser comado como uma reflexão exemplar sobre vários outros conceitos operacionais do Direito.

Nesses termos e limites, cumpre-se o objetivo de demonstrar o potencial formativo profissional do eixo fundamental por uma via direta. Obviamente, isso não significa diminuir a importância das justificativas indiretas, vistas no capítulo introdutório. De igual modo, o fato de demonstrar a relevância de conteúdos do eixo de formação fundamental não implica diminuir a importância das atividades e conteúdo dos eixos profissional e prático e nem de suas respectivas obras de referência. Não seria desejável ou razoável esperar que autores que pesquisam e escrevem sobre ramos muito específicos dos eixos profissional e prático pudessem contemplar todos os aspectos relevantes que são próprios do eixo fundamental. Cada um deles exerce uma função específica e, pelo que foi exposto, não podem ser ignorados sem prejuízo à formação profissional do estudante de Direito.

\section{REFERÊNCIAS}

BUENO, Cassio Scarpinella. Manual de direito processual civil: inteiramente estruturado à luz do novo CPC - Lei n. 13.105, de 16-3-2015. São Paulo: Saraiva, 2015.

CÂMARA, Alexandre Freitas. O novo processo civil brasileiro. 3. ed. São Paulo: Atlas, 2017.

CNE. Resolução CNE/CES 9/2004. Diário Oficial da União, Brasília, $1^{\circ}$ de outubro de 2004, Seção 1, p. 17. Disponível em <http://portal.mec.gov.br/cne/arquivos/pdf/rces09_04.pdf> Acessado em 13 de agosto de 2017.

CNE. Parecer CNE/CES 55/2004. Disponível em $<$ http://portal.mec.gov.br/cne/arquivos/pdf/2004/ces0055_2004.pdf> Acessado em 13 de agosto de 2017.

DIDIER JÚNIOR, Fredie. Curso de Direito Processual Civil: introdução ao direito processual civil, parte geral e processo de conhecimento. Vol. 1. 17. ed. Salvador: Editora Jus Podivm, 2015.

DONIZETTI, Elpídio. Curso didático de direito processual civil. 19. ed. revisada e 
completamente reformulada conforme o Novo CPC - Lei 13.105, de 16 de março de 2015 e atualizada de acordo com a Lei 13.256, de 04 de fevereiro de 2016. São Paulo: Atlas, 2016.

KELSEN, Hans. O problema da justiça. Trad. João Baptista Machado. $3^{\text {a }}$ ed. São Paulo: Martins Fontes. 1998.

MARINONI, Luiz Guilherme; ARENHART, Sérgio Cruz; MITIDIERO, Daniel. Novo curso de processo civil: teoria do processo civil. Vol. 1 [livro eletrônico]. 3. ed. rev., atual. e ampli. São Paulo: Editora Revista dos Tribunais, 2017.

MONTENEGRO FILHO, Mizael. Curso de Direito Processual Civil. 12. ed. ref. e atual. São Paulo: Atlas, 2016.

NEVES, Daniel Amorim Assumpção. Manual de direito processual civil. 8. ed. Salvador: Editora Jus Podivm, 2016.

PERELMANN, Chaïm. Ética e Direito. Trad. Maria Ermantina Galvão G. Pereira. São Paulo: Martins Fontes, 1996.

ROSS, Alf. Direito e Justiça. Trad. Edson Bini. Rev. Alysson Leandro Mascaro. Bauru: EDIPRO, 2000.

SOUZA, Rubin Assis da Silveira. Técnicas pedagógicas passo-a-passo de ensino de filosofia para o jurista desocupado. Captura Críptica. Florianópolis, n.4., v.1., jan./dez. 2013. p. 9-18. Disponível em <http://capturacriptica.ccj.ufsc.br/wp-content/uploads/captura_criptica__v4n1_completo.pdf> Acessado em 15 de agosto de 2017.

STF. Pesquisa de Jurisprudência. Disponível em <http://www.stf.jus.br/portal/jurisprudencia/pesquisarJurisprudencia.asp> Acessado em 13 de agosto de 2017.

THEODORO JÚNIOR, Humberto. Curso de Direito Processual Civil: Teoria geral do direito processual civil, processo de conhecimento e procedimento comum - vol. I. 56. ed. rev., atual. e ampl. Rio de Janeiro: Forense, 2015.

VERONESE, Alexandre. Advogados e ensino jurídico. Jota. Disponível em $<$ https://jota.info/colunas/judiciario-e-sociedade/judiciario-e-sociedade-advogados-e-ensinojuridico-11122015> Acessado em 13 de agosto de 2017. 